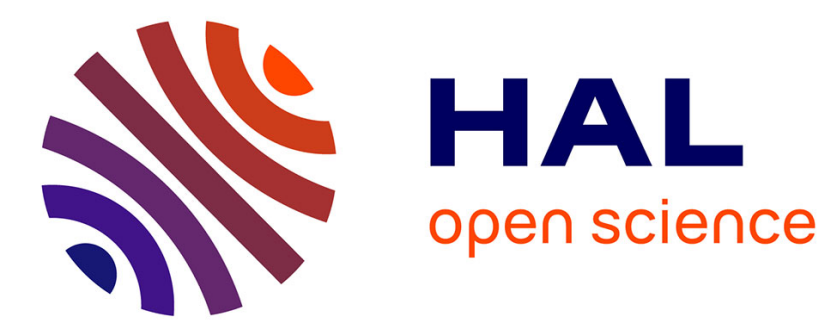

\title{
Coextrusion of Multifunctional Smart Sensors
}

Sampada Bodkhe, Clara Noonan, Frederick Gosselin, Daniel Therriault

\section{To cite this version:}

Sampada Bodkhe, Clara Noonan, Frederick Gosselin, Daniel Therriault. Coextrusion of Multifunctional Smart Sensors. Advanced Engineering Materials, 2018, 20 (10), pp.1800206. 10.1002/adem.201800206 . hal-03188309

\section{HAL Id: hal-03188309 \\ https://hal.science/hal-03188309}

Submitted on 1 Apr 2021

HAL is a multi-disciplinary open access archive for the deposit and dissemination of scientific research documents, whether they are published or not. The documents may come from teaching and research institutions in France or abroad, or from public or private research centers.
L'archive ouverte pluridisciplinaire HAL, est destinée au dépôt et à la diffusion de documents scientifiques de niveau recherche, publiés ou non, émanant des établissements d'enseignement et de recherche français ou étrangers, des laboratoires publics ou privés. 


\section{WILEY-VCH}

\section{Coextrusion of Multifunctional Smart Sensors}

Sampada Bodkhe, Clara Noonan, Frederick P Gosselin and Daniel Therriault*

S Bodkhe, C Noonan, Prof. F P Gosselin, Prof. D Therriault

Laboratory for Multiscale Mechanics,

Department of Mechanical Engineering,

Centre for Applied Research on Polymers and Composites (CREPEC),

Polytechnique Montreal, C.P. 6079, succ. Centre-Ville, Montreal, QC H3C 3A7, Canada

E-mail: daniel.therriault@polymtl.ca

Keywords: coextrusion, nanocomposite, piezoelectric, sensor, wearables

Three-dimensional (3D) printing of a piezoelectric sensor conventionally involves a minimum of three steps: fabrication of the sensor structure, electrode deposition to collect the generated charges and electrical poling. Here, we report a novel approach to fabricate a working piezoelectric sensor with its electrodes in a single step. We optimize the rheological characteristics of a piezoelectric nanocomposite ink, formulated and processed to work without the need for poling, and a metallic conductive paint for coextrusion. We then employ solvent evaporation-assisted 3D printing to coextrude ready-to-use sensors. The process fabricates conformal sensors, 3D self-supported cat whiskers with aspect ratios over 15 , and filaments spanning over $2 \mathrm{~cm}$. We present potential applications in the form of aero-elastic sensors and smart active thread for wearable electronics. We print sensors directly on fused deposition modelling printed miniature wings to monitor aero-elastic stability. In another application, we use the coextruded filament in the form of a piezoelectric thread for wearable sensors for knee-joint and respiration monitoring. The self-powered piezoelectric sensing elements are an attractive alternative for customized, multi-material applications where each watt and each gram counts such as wearables, and micro-drones. The process is adaptable to other multi-material and multi-component printing needs beyond piezoelectric materials.

\section{Introduction}




\section{WILEY-VCH}

Remote monitoring is imperative to extract information about the environment, flight conditions and structural damage to complement the performance of air-vehicles and automobile. The weight and aerodynamics are paramount to the structures, along with mechanical durability and smooth functioning in isolated locations inaccessible to power. ${ }^{[1,2]}$ $3 \mathrm{D}$ printing of piezoelectric materials serves as an apt tool to integrate sensors directly on the surface or embed them inside the parts to be monitored.

On the other hand, wearable sensors are increasingly sought after over conventional ambulatory diagnostics for monitoring vital signs in military, sports, and rehabilitation prosthetics owing to their foremost advantage of real-time unobtrusive electrophysiological analysis combined with low cost (over 10 times lower), portability, and versatility. ${ }^{[3,4]}$ Present day wearable sensors rely on resistive $e^{[5,6,7,8]}$ or capacitive ${ }^{[9,10]}$ technology operating with bulky batteries that need to be frequently recharged and replaced, whereas piezoelectric sensors serve as self-powered alternatives. ${ }^{[11,12,13]}$ The components - electronics and multifunctional materials (material- making the clothing intelligent), are either embedded or woven in the fabric or directly embedded into the fibers themselves. ${ }^{[14]}$

Piezoelectric sensors generate electric signals linearly proportional to mechanical deformation and come with the advantages of larger band-width, low-response time, and low operational costs. ${ }^{[15]}$ Ceramics have dominated the piezoelectric market for decades due to the inefficiency of the piezoelectric polymers. Biocompatible, compliant, conformal and tough piezoelectric ceramic composites with polymers now overcome the limitations of brittle and rigid ceramics. ${ }^{[11,13,16,17,18]}$ However things have not changed much in the form in which sensors continue to be fabricated: fibers ${ }^{[19,20]}$ or films. ${ }^{[13,21]}$ The sensors are then either bonded, ${ }^{[22,23]}$ or strapped ${ }^{[24]}$ at the sensing locations increasing non-conformability with the substrate, thus leading to inconsistent and erroneous results. Furthermore, electrodes to collect the generated charges are typically coated, ${ }^{[25]}$ screen-printed, ${ }^{[23]}$ or deposited ${ }^{[26]}$ which is multi-stepped, time-consuming, and arduous for miniature slender structures. Conventional 


\section{WILEY-VCH}

piezoelectric sensor fabrication processes entail additional poling steps, and often necessitate clean-room environment, which form a bottleneck in an industry setting. It is thus exigent to devise a process adept to industrial production. To apply the piezoelectric fiber into smart textiles, its diameter needs to match that of the fabric's thread. Unlike the metallic resistive sensors, the piezoelectric sensor requires two electrodes to collect and transport the generated charges. However, coating, and depositing electrodes form additional processing steps increasing the complexity and costs.

We proffer an unprecedented technique to three-dimensionally (3D) print flexible piezoelectric sensors with two co-fabricated electrodes in a single step quintessential for integrated and complex-shaped sensors and present their applications on two fronts: as active threads to study knee-motion and respiration in wearable electronics and aero-elastic monitoring of 3D printed wings. We investigate the physical properties affecting the printability and piezoelectricity of the coextruded system and show the adeptness of the process through various 3D printed structures.

\section{Results and Discussion}

We have recently demonstrated successful 3D printing of a piezoelectric nanocomposite ink with 10 wt. \% barium titanate nanoparticles $\left(\mathrm{BaTiO}_{3} \mathrm{NPs}\right)$ in polyvinylidene fluoride (PVDF) matrix. ${ }^{[27]}$ The as-fabricated 3D structures possessed a $d_{31}$ constant of $\sim 18 \mathrm{pC} \mathrm{N}^{-1}$ without any poling. In this work, we coextrude (see details in SI and Supplementary Movie 1) this piezoelectric ink with a commercial silver ink to form piezoelectric sensors in a single step (see Figure 1a). We printed various kinds of piezoelectric structures: a filament (see Figure $1 \mathrm{~b}$ and $\mathrm{c}$ ), freestanding whiskers of a cat with aspect ratio of 15 (see Figure 1d), conformal features on a hemisphere (see Figure 1e) and filaments spanning up to $20 \mathrm{~mm}$ (print diameter $=0.84 \mathrm{~mm}$, see Figure 1f). The SEM image of the cross-section reveals that the silver electrodes were formed on a small region on the outer surface of the filament (EDS details in 


\section{WILEY-VCH}

SI). We believe uneven evaporation rates of the two inks turn the expected circular crosssection closer to an ellipse (see Section S3).

For coextrusion printing with interlayer stability and layer uniformity the two fluids should have similar rheological behavior ${ }^{[28]}$, and exhibit shear thinning properties, ${ }^{[29]}$ and finally equal flow velocities for both the inks are achievable only when the outer layer has a lower viscosity. ${ }^{[30]}$ We optimized the concentration of the two inks in order to achieve similar rheological properties at the same time without compromising the compliance and thus, the mechanical sensitivity ${ }^{[21]}$ of the printed filament (see Section S4 and S5). Piezoelectric materials are shown to measure the strain up to $1.2 \%^{[21]}$ and most human activities fall in the low frequency range of $0.25-2 \mathrm{~Hz} \cdot{ }^{[25]}$ Our piezoelectric thread completely reproduces the applied mechanical cyclic loading with $1 \%$ strain at a frequency of $2 \mathrm{~Hz}$ (see Section S6). To demonstrate the 3D printability of the current system, an aero-elasticity monitoring sensor in the shape of a typical strain gauge was printed on top of a fused deposition modeling (FDM)-printed beam shaped-like an insect wing (see Figure 2a). We assessed the sensitivity of the sensor to: (i) the magnitude and frequency of the applied forces, (ii) mechanical obstructions, and (iii) any changes in the surrounding wind flow, by mounting the wing on an electromagnetic shaker (see Figure S7) and exciting it at various forcing frequencies and amplitudes. The insets in Figure 2a confirm that there was no shorting between the electrodes at the turns and corners of the sensor. The response of the sensor (see Figure $2 b$ ) to the applied sinusoidal mechanical input $(4 \mathrm{~Hz})$ to the shaker was mostly linear as expected of piezoelectric materials. The sensor further reproduced the sinusoidal input very well for all the frequencies tested between $0.2 \mathrm{~Hz}$ and $15 \mathrm{~Hz}$; a few of them are presented in Figure 2c. We then applied a sinusoidal input of $1 \mathrm{~Hz}$ to the wing (see Figure $2 \mathrm{~d}$ and $2 \mathrm{e}$ ). The response in the absence of any external perturbations is a regular sine curve. The sensor picked up physical obstructions (see Figure 2e) and flow perturbations (see Figure 2f) to the wing as 


\section{WILEY-VCH}

seen by the disturbances in the electrical output signal establishing its applicability for monitoring the aero-elastic behavior of the wing.

We wove the sensors into a knee-stabilizer (see Figure 3a) that offered extensive contact with the joints aiding firm movements. A single unpoled filament sewn into the knee support detected and distinguished joint movements. We studied the response of the sensor during dynamic activities while cycling (Figure $3 b$ ) which is a combination of the continuous form of the two static motions (see Section 8 in SI). The voltage response curve is a resultant of the affect of the motion of all the parts: hip, knee and ankle. ${ }^{[31]}$ The origin of the system is when the leg is fully stretched. The superposed red curve over the pictures corresponds to the anklemotion in Cartesian coordinates. A and B are the points at which the thigh forms a right angle with the calf. The first positive peak in the piezoelectric response curve (Figure 3c) corresponds to the bending of the leg behind the knee making a right angle. The negative peak occurs when the leg comes in the forward position and the thigh is parallel to the ground making the second right angle. Our sensor accurately detected the cycling frequency and the response is in complete accordance with the angular velocity (see Figure 3c). The small lag seen in the signals is mostly due to the lower sampling frequency of the video recording (59.9 fps) as compared with the voltage acquisition $(2000 \mathrm{~Hz})$. The noisy peaks in the voltage signal can be attributed to wrinkling of the filaments which are not well supported as compared to those printed directly on the wings. The variation of maximum voltage in each cycle with the cycling rate (see Figure S9) for two different set of tests (Figure 3c and another cycle not shown here) ascertains that higher the cycling speed larger will be the voltage obtained from the sensor.

After studying the sensors for large-scale motion, we studied their sensitivity to detect smallscale motion as in respiration. Respiration is a physiological phenomenon involving the expansion of the chest cavity during inhalation, and its contraction during exhalation forming one respiration cycle. For normal breathing at rest, the respiration rate is around 12-20 cycles 


\section{WILEY-VCH}

per min. ${ }^{[32]}$ A sensor sewn into a t-shirt on the side of the thorax, normal to the axillary lines (see Figure 3d), tracked the breathing rhythm of the wearer. During breathing tests the amplitude of the voltage response from the sensor (see Figure $3 \mathrm{e}$ and $\mathrm{f}$ ) corresponded to the breathing volume while the frequency to the respiration rate. The breathing sensor measured respiration rates very well (see Supplementary Table 1 and 2). The sensor aided in differentiating between the types of breathing (see Figure $3 \mathrm{e}$ and $\mathrm{f}$ ): slow or fast, and shallow or deep based on the frequency and amplitude of the voltage, respectively.

\section{Conclusions}

We have demonstrated a novel technique to form ready to use piezoelectric sensors with their electrodes in a single step. Our piezoelectric sensors successfully detect the frequency and the generated voltage is linearly proportional to the applied strain. Sensors determining the speed of the motion and distinguishing one movement from the other when directly woven into the clothing are convenient and comfortable to wear and wash without adversely affect the skin. Additional piezoelectric filaments embedded in the textiles could act as a power source to the attached electronics ${ }^{[21]}$ avoiding batteries and entangling wires. ${ }^{[25]}$ Our technique demonstrates the feasibility of a multi-material printing approach where the structure and the sensor could be printed in a single facility at the same time. 3D printability of these sensors would allow conformability to various automobile and aerospace components for structural health monitoring. The process promises potential towards a series of other set of materials and applications that benefit from coextrusion. ${ }^{[33]}$

\section{Experimental Section}

Materials: Preparation of $\mathrm{PVDF} / \mathrm{BaTiO}_{3}$ nanocomposite: We ball-milled (1080 cycles per min; SPEX SamplePrep ${ }^{\mathrm{TM}} 8000$ Series Mixer/Mill ${ }^{\mathrm{TM}}$ ) a mixture of $0.31 \mathrm{~g}$ of $\mathrm{BaTiO}_{3}$ nanoparticles (10 wt.\%, $99.9 \%$ purity, 100 nm; Nanostructured \& Amorphous materials Inc) and $3.1 \mathrm{~g}$ of PVDF (Sigma Aldrich) with $4 \mathrm{~mL}$ dimethyl formamide (DMF, Alfa Aesar), 6 


\section{WILEY-VCH}

$\mathrm{mL}$ acetone $(\mathrm{BDH})$ and $0.6 \mathrm{~mL}(\mathrm{DMSO}$, Sigma Aldrich) for $20 \mathrm{~min}$. Silver print conductive liquid paint (0.2 Ohm x mil resistivity; MG Chemicals) formed the electrodes.

Printing: We loaded the piezoelectric and the silver inks into $3 \mathrm{~mL}$ syringe barrels (see Figure 1a-d) and placed the syringe barrels into a pneumatically operated dispensing system (HP-7X, EFD) to apply precise pressures $(0.1-4.0 \mathrm{MPa})$ to coextrude the filaments through tapered nozzles (diameter, $d=410 \mu \mathrm{m}-1.6 \mathrm{~mm}$ ). We used a $840 \mu \mathrm{m}$ nozzle to print all the structures. We coextruded piezoelectric threads with $0.1-0.15 \mathrm{MPa}$ extrusion pressures $(P)$. An interfacing software transferred structure geometries in the form of Cartesian coordinates and print speeds to a robotic dispensing system (I\&J2200-4, I\&J Fisnar Inc.) via (JR points for dispensing, Janome Sewing Machine). We printed cat whiskers at $P=0.04 \mathrm{MPa}$ and stage speeds ( $v$ ) from $2-4 \mathrm{~mm} \mathrm{~s}^{-1}$, piezoelectric strain sensors on FDM (FDM details in SI) printed wings with $P=0.08-0.12 \mathrm{MPa}$ and $v=35 \mathrm{~mm} \mathrm{~s}^{-1}$, conformal sensors with $P=60 \mathrm{kPa}$ and $v$ $=10 \mathrm{~mm} \mathrm{~s}^{-1}$ and spanning filaments with $P=150 \mathrm{kPa}$ and $v=20 \mathrm{~mm} \mathrm{~s}^{-1}$.

Characterization: Optical microscopy (BX-61 Olympus; Image-Pro plus V5 an image processing software from Media Cybernetics) permitted the measurement of the thickness and morphology of the filaments and 3D printed structures. A field emission scanning electron microscope (FE-SEM; JEOL JSM-7600TFE) with a low angle back-scattered electron detector obtained high contrast images of the coextruded filament cross-section.

Data Acquisition: For all the sensors, we attached copper tape (3M Canada) at the ends of the piezoelectric thread to form an interface for charge collection. A charge amplifier (Measurement Specialties) with an NI-9239 data acquisition system attached to a USB carrier NI-9162 (National Instruments) converted the charges collected from the sensors into readable voltages to read with a LabVIEW interface.

Aero-elastic monitoring: We coextruded the sensors along with their electrodes and 3D printed them on top of a FDM printed insect wing in the shape of a strain gauge (Figure 4a). We screwed the wing on an electromagnetic shaker (The Mode Shop Inc. Model K2007E01). 


\section{WILEY-VCH}

A waveform generator (TE GAM, Model 2720), excited the shaker with input voltage (0.02 to

$0.12 \mathrm{~V})$ in the frequency range $(0.2$ to $20 \mathrm{~Hz})$. A copper mesh covered the entire test set up for electro-magnetic shielding. We made mechanical perturbations to the wing by hitting it with a slender object, and simulated gusts using a hair dryer (Revlon, Ionic ceramic), at its highest speed, held vertically above the wing.

Wearable sensors: Piezoelectric filaments were woven into a clinical elastic knee stabilizer (see Figure 3a) (Formedica®). A commercial freeware, Kinovea (0.8.15), extracted motion data from the recorded videos (60 fps; Canon EOS Rebel T4i) for comparison with the response from our piezoelectric sensors during the static tests. In case of cycling, Image $\mathbf{J}$ was used to track the motion and determine the angular frequency. Motion extraction details are provided in the SI. Cycling tests were performed on a clinical bike (Sport Excaliber, Lode BV Medical Technology) at a mechanical power of $80 \mathrm{~W}$. To monitor respiration, we wove the thread into a tight t-shirt on the left side of the thoracic cavity, parallel to the ribs (see Figure 3d). Conducting threads embroidered into the t-shirt formed the electrical connections from the sensor to avoid any noise from moving wires. We tested for two breathing types at rest: quick/shallow and slow/deep.

\section{Supporting Information}

Supporting Information is available from the Wiley Online Library or from the author.

\section{Acknowledgements}

The authors acknowledge the financial support from Natural Sciences and Engineering Research Council of Canada (NSERC, \#RGPIN312568-2013) and Canada Research Chair (\#CRC950-216943). The authors thank Prof. Jonathan Tremblay, Kinesiology department, University of Montreal, for the access to the research bike and breathing monitoring equipment and Mr. Nicolas Leduc-Savard for assistance with the logistics. The authors also thank Ms. Isabelle Nowlan, and the Laboratory for Acoustics and Vibration Analysis and the Laboratory for Electrical Energy at Polytechnique Montreal for the electromechanical shaker and the function generator, respectively.

Received: ((will be filled in by the editorial staff))

Revised: ((will be filled in by the editorial staff)) Published online: ((will be filled in by the editorial staff)) 


\section{WILEY-VCH}

References

[1] K.-I. Park, J. H. Son, G.-T. Hwang, C. K. Jeong, J. Ryu, M. Koo, I. Choi, S. H. Lee, M. Byun, Z. L. Wang, K. J. Lee, Adv. Mater. 2014, 26, 2514.

[2] K.-I. Park, M. Lee, Y. Liu, S. Moon, G.-T. Hwang, G. Zhu, J. E. Kim, S. O. Kim, D. K. Kim, Z. L. Wang, K. J. Lee, Adv. Mater. 2012, 24, 2999.

[3] S. Chen, J. Lach, B. Lo, G. Z. Yang, IEEE Journal of Biomedical and Health Informatics 2016, 20, 1521.

[4] V. Koncar, in Smart Textiles and their Applications, Woodhead Publishing, Oxford 2016, 1 .

[5] L. Beker, A. Benet, A. T. Meybodi, B. Eovino, A. P. Pisano, L. Lin, Biomed. Microdevices 2017, 19, 32.

[6] G. Y. Bae, S. W. Pak, D. Kim, G. Lee, D. H. Kim, Y. Chung, K. Cho, Adv. Mater. 2016, 28, 5300 .

[7] F. Lorussi, W. Rocchia, E. P. Scilingo, A. Tognetti, D. D. Rossi, IEEE Sens. J. 2004, 4, 807.

[8] C. Mattmann, F. Clemens, G. Tröster, Sensors 2008, 8, 3719.

[9] J.-Y. Sun, C. Keplinger, G. M. Whitesides, Z. Suo, Adv. Mater. 2014, 26, 7608.

[10] R. Li, Y. Si, Z. Zhu, Y. Guo, Y. Zhang, N. Pan, G. Sun, T. Pan, Adv. Mater., 1700253.

[11] D. Y. Park, D. J. Joe, D. H. Kim, H. Park, J. H. Han, C. K. Jeong, H. Park, J. G. Park, B. Joung, K. J. Lee, Adv. Mater., 1702308.

[12] Y.-K. Fuh, P.-C. Chen, Z.-M. Huang, H.-C. Ho, Nano Energy 2015, 11, 671.

[13] C. Dagdeviren, Y. Shi, P. Joe, R. Ghaffari, G. Balooch, K. Usgaonkar, O. Gur, P. L. Tran, J. R. Crosby, M. Meyer, Y. Su, R. Chad Webb, A. S. Tedesco, M. J. Slepian, Y. Huang, J. A. Rogers, Nat. Mater. 2015, 14, 728.

[14] M. Stoppa, A. Chiolerio, Sensors 2014, 14, 11957.

[15] H. Gullapalli, V. S. M. Vemuru, A. Kumar, A. Botello-Mendez, R. Vajtai, M.

Terrones, S. Nagarajaiah, P. M. Ajayan, Small 2010, 6, 1641.

[16] L. Persano, C. Dagdeviren, C. Maruccio, L. De Lorenzis, D. Pisignano, Adv. Mater. 2014, 26, 7574.

[17] D. Ponnamma, M. M. Chamakh, K. Deshmukh, M. Basheer Ahamed, A. Erturk, P. Sharma, M. A.-A. Al-Maadeed, in Smart Polymer Nanocomposites: Energy Harvesting, SelfHealing and Shape Memory Applications, (Eds: D. Ponnamma, K. K. Sadasivuni, J.-J. Cabibihan, M. A.-A. Al-Maadeed), Springer International Publishing, Cham 2017, 77.

[18] H. Wu, Y. Huang, F. Xu, Y. Duan, Z. Yin, Adv. Mater. 2016, $28,9881$.

[19] J. Chang, M. Dommer, C. Chang, L. Lin, Nano Energy 2012, 1, 356.

[20] C.-T. Pan, C.-K. Yen, H.-C. Wu, L. Lin, Y.-S. Lu, J. C.-C. Huang, S.-W. Kuo, J.

Mater. Chem. A 2015, 3, 6835.

[21] T. Q. Trung, N.-E. Lee, Adv. Mater. 2016, 28, 4338.

[22] Q. Sun, W. Seung, B. J. Kim, S. Seo, S.-W. Kim, J. H. Cho, Adv. Mater. 2015, 27 , 3411.

[23] S. Y. Chung, S. Kim, J.-H. Lee, K. Kim, S.-W. Kim, C.-Y. Kang, S.-J. Yoon, Y. S. Kim, Adv. Mater. 2012, 24, 6022.

[24] D. Aidin, V. Jérémie, Smart Mater. Struct. 2014, 23, 105020.

[25] M. Lee, C.-Y. Chen, S. Wang, S. N. Cha, Y. J. Park, J. M. Kim, L.-J. Chou, Z. L. Wang, Adv. Mater. 2012, 24, 1759.

[26] F. Li, W. Liu, C. Stefanini, X. Fu, P. Dario, Sensors 2010, 10, 994.

[27] S. Bodkhe, G. Turcot, F. P. Gosselin, D. Therriault, ACS Appl. Mater. Interfaces 2017, 9, 20833.

[28] J. P. Chown, J. M. Healey, Google Patents, 1976.

[29] D. Therriault, R. F. Shepherd, S. R. White, J. A. Lewis, Adv. Mater. 2005, 17, 395. 


\section{WILEY-VCH}

[30] J. Dooley, "Determining the Processability of Multilayer Coextruded Structures", presented at PLACE Conference, St. Louis, MO, Septemeber 16-20, 2007.

[31] Vol. 2017, Quinticsports.

[32] K. Subrata Kumar, K. Shinya, S. Minoru, Jpn. J. Appl. Phys. 2013, 52, 04CL05.

[33] P. Mistry, A. Aied, M. Alexander, K. Shakesheff, A. Bennett, J. Yang, Macromol. Biosci. 2017, 17, 1600472. 


\section{WILEY-VCH}

(a)
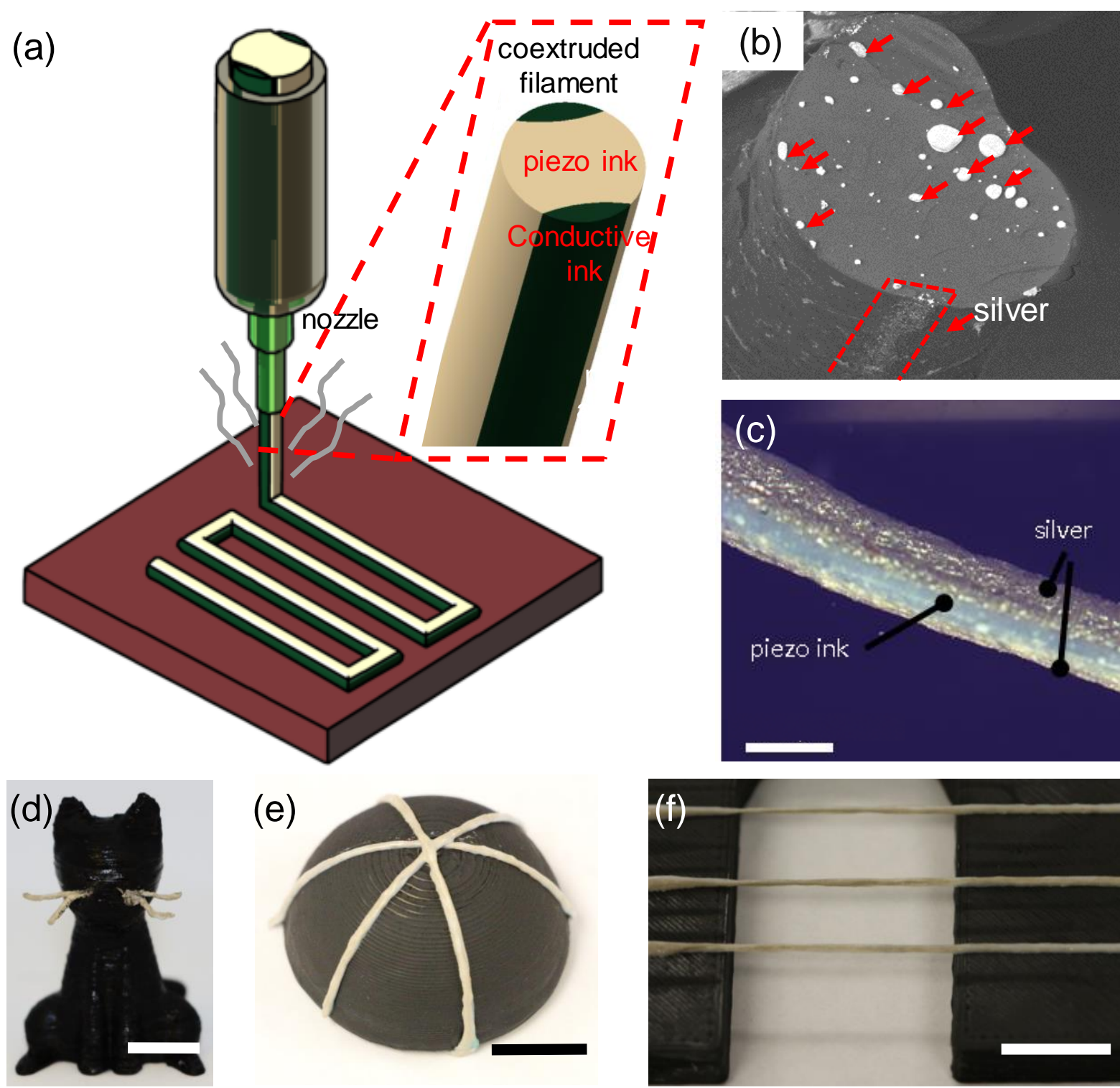

Figure 1. a) Schematic of the coextrusion process, inset: cross-section of the coextruded filament showing the piezoelectric and conductive inks) b) SEM image of cold fractured cross-section of the coextruded filament (scale bar $=100 \mu \mathrm{m}$ ), major NP agglomerates are indicated with red arrows, and the silver electrode is highlighted with a red border; photograph of coextruded c) microscopic image of the piezoelectric thread (scale bar $=500$ $\mu \mathrm{m}) ; \mathrm{d})$ freestanding whiskers printed on a FDM printed cat (scale bar $=10 \mathrm{~mm})$; e) conformal sensors printed on a hemisphere (scale bar $=5 \mathrm{~mm}$ ); and f) spanning filaments $($ scale bar $=10 \mathrm{~mm})$. (Printing parameters: nozzle diameter $=840 \mu \mathrm{m}$, extrusion pressure $=$ $0.04-0.2 \mathrm{MPa}$, speed $\left.=2-20 \mathrm{~mm} \mathrm{~s}^{-1}\right)$. 

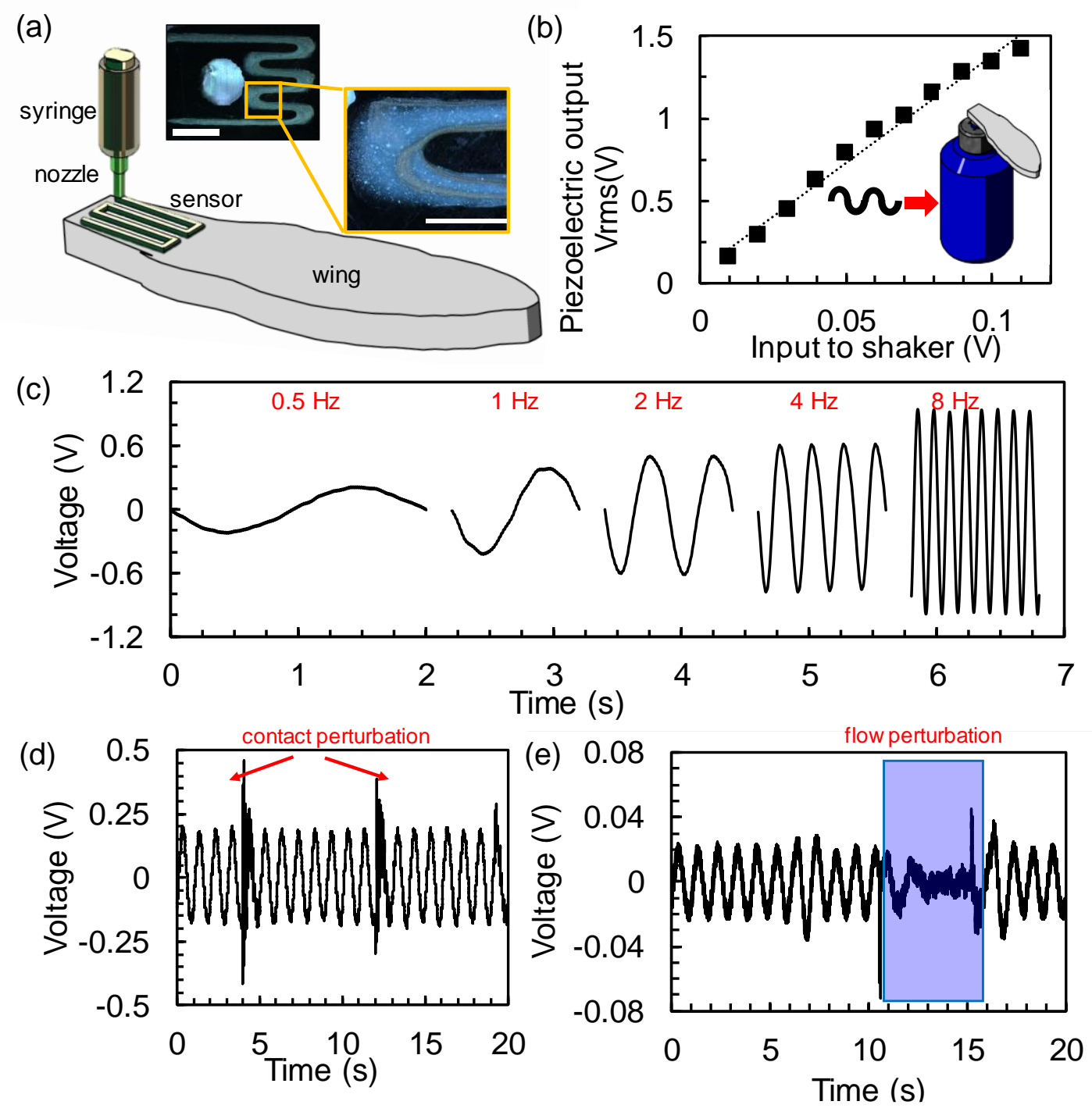

Figure 2. a) Schematic of one step sensor being 3D printed on a FDM printed wing, inset: microscopic image of the sensor on the wing (top) and enlarged view of the sensor showing the piezoelectric material (white) and two silver electrodes (bottom); b) piezoelectric voltage (RMS) output from the sensor as a function of voltage input to an electromagnetic shaker (frequency $=4 \mathrm{~Hz}$ ), inset: the wing mounted on an electromagnetic shaker c) output voltage responses for $0.5,1,2,4$ and $8 \mathrm{~Hz}$ input frequencies to the wing (input amplitude $=0.05 \mathrm{~V}$ ); variation in the response of the sensor when disturbed d) mechanically and e) aerodynamically (shaker input frequency $=1 \mathrm{~Hz}$; amplitude $=0.05 \mathrm{~V}$ ). 

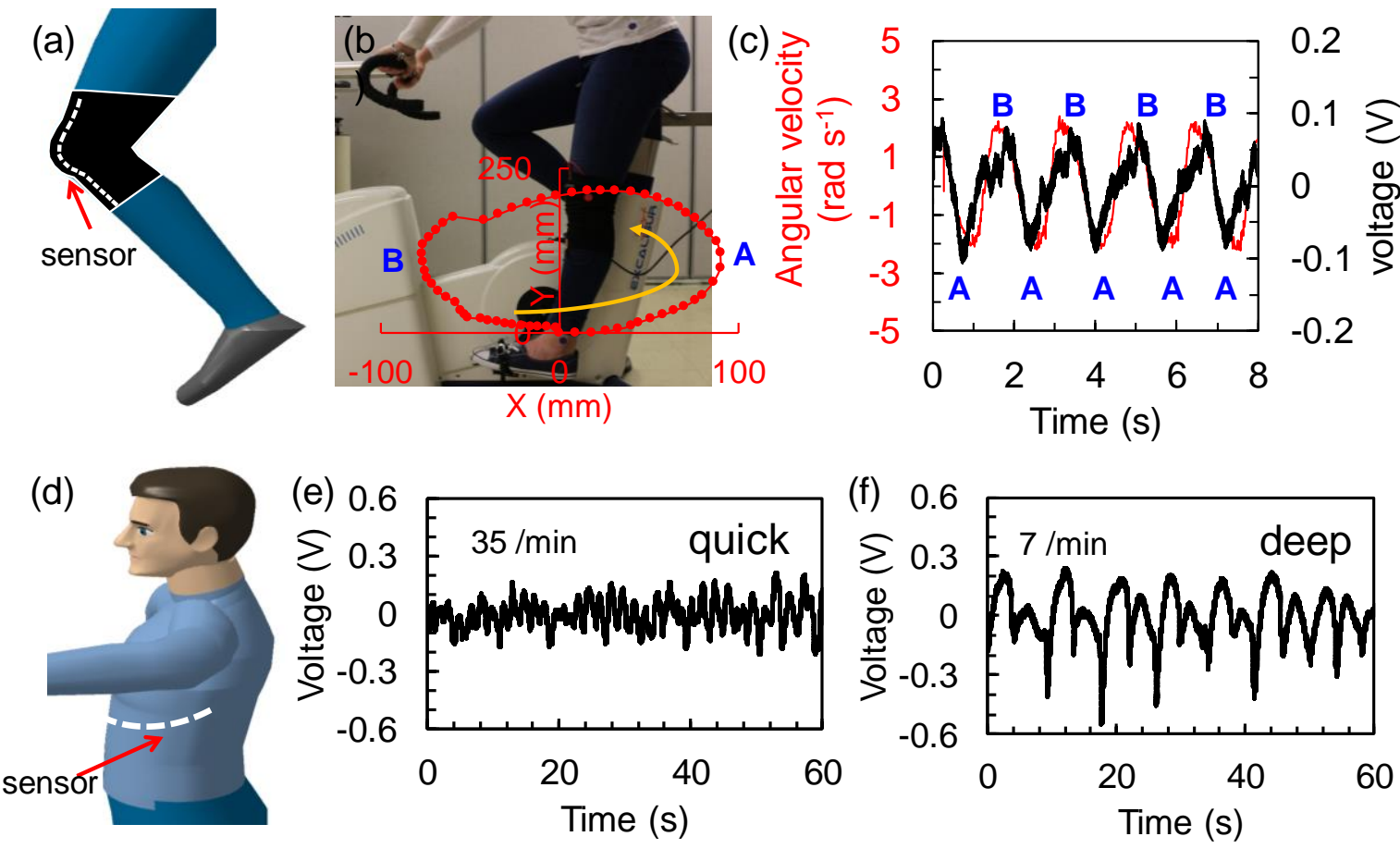

Figure 3. Wearable sensors tests: a) Schematic depicting the sensor sewn on a knee-stabilizer; b) photograph of the cycling test: red plot shows the path of the ankle during cycling as extracted from the video frames and the yellow arrow shows the cycling direction; c) plot of angular velocity obtained from the recorded video and voltage output of the sensor during cycling; d) schematic of the piezo thread woven into a T-shirt; breathing sensor output during e) shallow/quick breathing, and f) deep/slow breathing for $1 \mathrm{~min}$. 


\section{WILEY-VCH}

We present one step three-dimensional printing of active piezoelectric sensors by coextruding a piezoelectric layer between two layers of silver. We demonstrate the potential of our technique in printing freestanding, conformal and spanning sensors, via two applications: aero-elastic monitoring and wearable sensors.

Keyword

S. Bodkhe, C. Noonan, F. P. Gosselin and D. Therriault*

Coextrusion of Multifunctional Smart Sensors

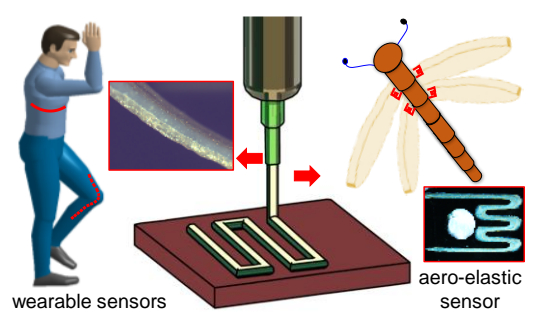




\section{WILEY-VCH}

Copyright WILEY-VCH Verlag GmbH \& Co. KGaA, 69469 Weinheim, Germany, 2016.

\section{Supporting Information}

\section{Coextrusion of Multifunctional Smart Sensors}

Sampada Bodkhe, Clara Noonan, Frederick P Gosselin and Daniel Therriault*

\section{Coextrusion of Multifunctional Smart Sensors}

Sampada Bodkhe, Clara Noonan, Frederick P Gosselin and Daniel Therriault*

\section{S1. Coextrusion Printing}

(a)

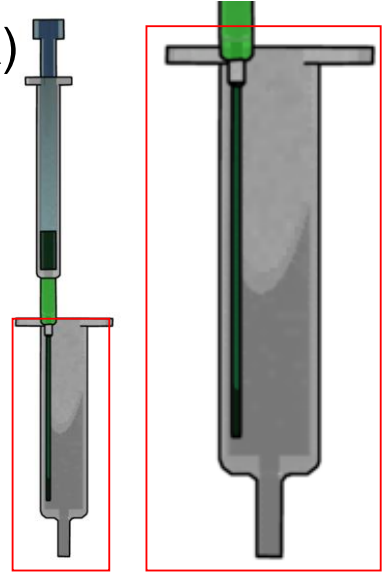

(b)

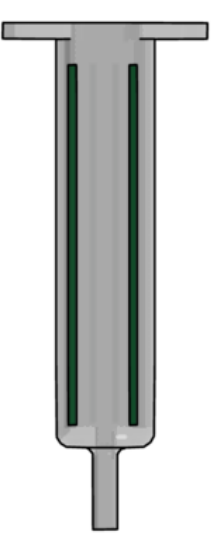

(c)

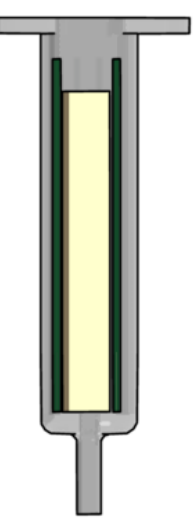

(d)

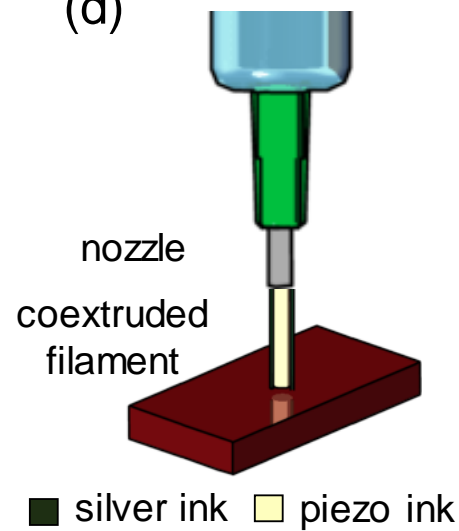

Figure S1: Printing: Schematic of the coextrusion process. a) cut-section of the syringe showing the painting of a silver filament on the wall; b) painting a second silver filament $180^{\circ}$ apart along the circumference of the syringe; c) filling the syringe with the piezoelectric ink;

d) coextruding the two inks from the syringe.

We first insert a commercial silver ink $(\mathrm{MG}-842)$ along the edges of a syringe ( $3 \mathrm{~mL})$ using a clinical syringe-needle system $(1 \mathrm{~mL})$ to form thin lines of silver on the walls as in Figure $\mathrm{S} 1$. We then quickly pour a solution of $\mathrm{PVDF} / \mathrm{BaTiO}_{3}$ nanocomposite into the syringe (see Figure S1c) to minimize the drying of the silver ink. Then we coextrude the two inks in the required design to attain the designed shapes.

\section{S2. SEM}




\section{WILEY-VCH}

A field emission scanning electron microscope (FE-SEM; JEOL JSM-7600TFE) with a low

angle back-scattered electron detector obtained high contrast images of the coextruded filament cross-section.
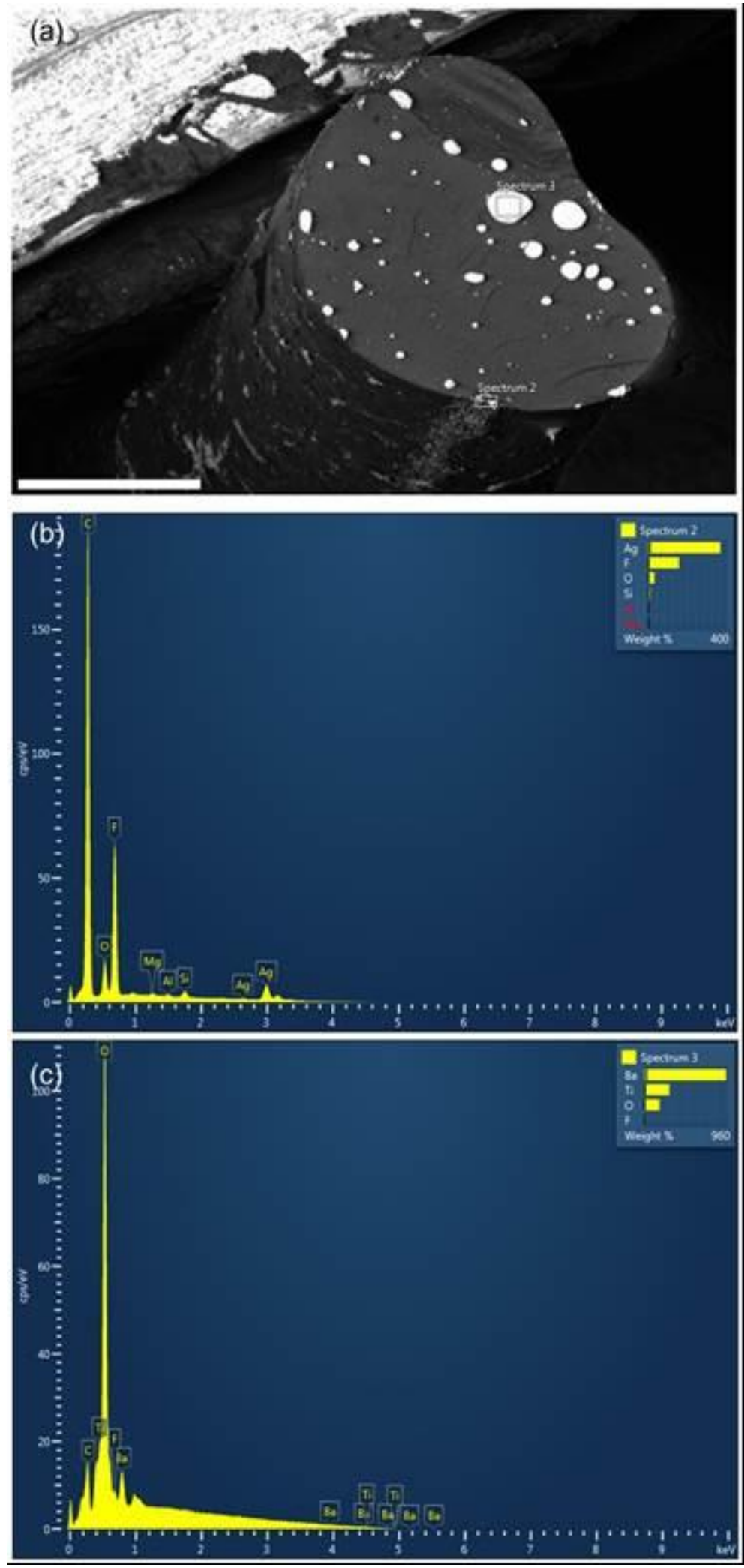


\section{WILEY-VCH}

Figure S2. a) SEM image of the cold fractured cross-section of the coextruded filament (scale bar $=250 \mu \mathrm{m}$ ); energy-dispersive spectroscopy (EDS) results for the regions selected in ' $\mathrm{a}$ ':

b) silver region, and c) $\mathrm{BaTiO}_{3}$ agglomerates.

\section{S3: Solvent evaporation tests}

Solvent evaporation tests were conducted by printing $10 \mathrm{~mm}$ long filaments with the inks $(d=$ $\left.840 \mu \mathrm{m} ; P=40 \mathrm{kPa} ; v=1 \mathrm{~mm} \mathrm{~s}^{-1}\right)$. A balance (Gh-200, A \& D) integrated with a recording software (RsCom Version 5.11, A \&D Company, limited) was used to monitor the weight of the filaments for $6 \mathrm{~h}$ (sampling frequency $=5 \mathrm{~Hz}$ ). Final weight of the filaments post complete evaporation of the solvents was recorded after $24 \mathrm{~h}$. The results (Figure $2 \mathrm{~b}$ ) are the average of volumetric shrinkage in three samples for each ink.

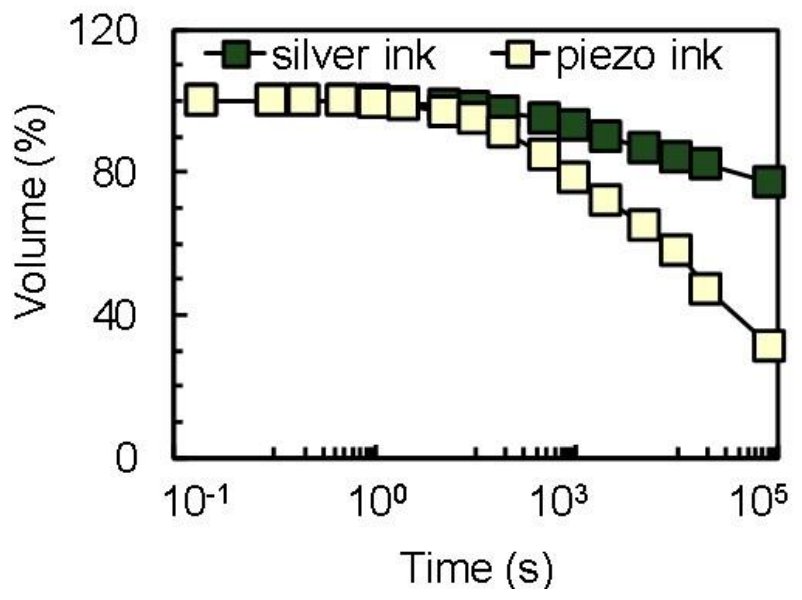

Figure S3. Volumetric shrinkage during solvent evaporation of piezoelectric and silver inks. The rate of evaporation of the solvents (see Figure S2) in the two inks dominates the shape of the cross-section of the printed filament or structure. Though the evaporation rates are similar at the onset of printing, in the final structure the piezoelectric ink shrinks the most (more than twice) as compared to the silver ink owing to the presence of a significant amount of solvents. We believe that this turns the expected circular cross-section closer to an ellipse (see Figure 1g). Rapid solvent evaporation renders the sensors ready to use right after extrusion. This technique fabricates sensors with feature sizes: $250 \mu \mathrm{m}-1.5 \mathrm{~mm}$, without intermixing the piezoelectric and the electrode materials. 


\section{WILEY-VCH}

\section{S4: Rheological characterization}

A rotational rheometer (Anton Parr, Physica MCR 501) provided the variation of viscosity versus shear rate for both the piezoelectric and silver inks. We used a rough concentric cylindrical geometry (CC 55) with a shear ramp rate of $0.1 \mathrm{~s}^{-1}$. Oil poured on the top of the inks during the tests prevented solvent evaporation.

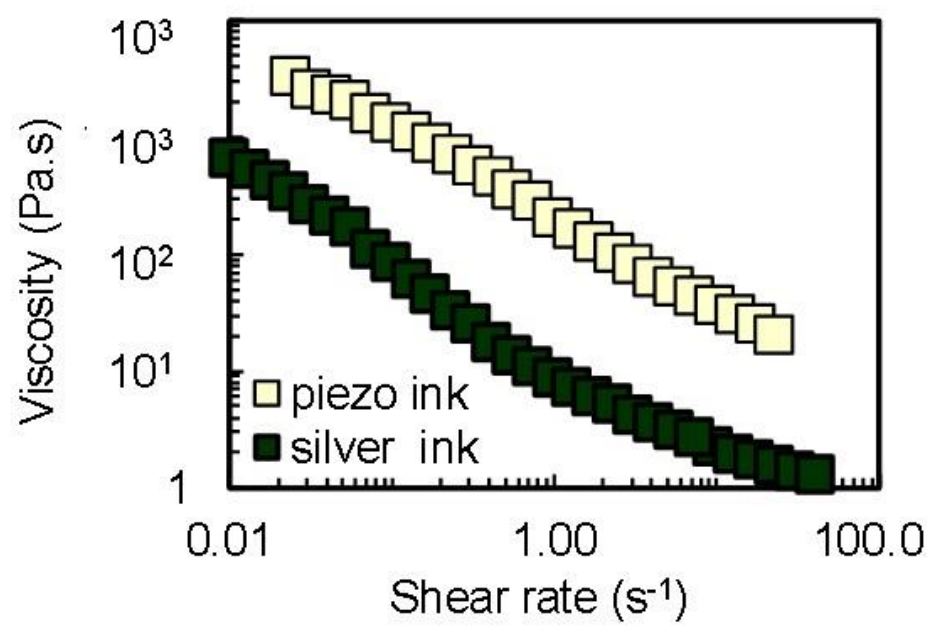

Figure S4. Log-log plots of viscosity versus shear rate.

For coextrusion without mixing or diffusion of one ink into the other, and to allow continuous extrusion of the two inks at any pressure, the two fluids should have similar rheological behavior. ${ }^{28}$ Further, shear thinning behavior in both the inks is significant to attain shape fidelity post-extrusion. ${ }^{29}$ Though the viscosities of the two materials vary at the given shear rates (see Figure S3), the curves for the two materials have similar slopes and comparable power law indices, $n$. Rheometer tests on the piezo and silver inks provide the power law indices as 0.77 and 0.79 , respectively. Interlayer stability and layer uniformity, i.e., equal flow velocities for both the inks are achievable only when the outer layer has a lower viscosity. ${ }^{30}$ It is desirable to extrude the material system at low flow-rates to be in the laminar flow regime, thus avoiding any turbulent mixing of the two materials.

\section{S5. Tensile tests}




\section{WILEY-VCH}

Uniaxial tensile tests (Insight electromechanical testing machine), performed at a strain rate $=$ $48 \mathrm{~mm} \mathrm{~min}{ }^{-1}$ with distance between the grips $=20 \mathrm{~mm}$ using a $5 \mathrm{~N}$ load cell according to ASTM D3822 standard evaluated the Young's moduli, strength and strain at break of the filaments. The reported values are an average of five successful samples (diameter $\sim 500 \mu \mathrm{m}$ ) tested until failure.

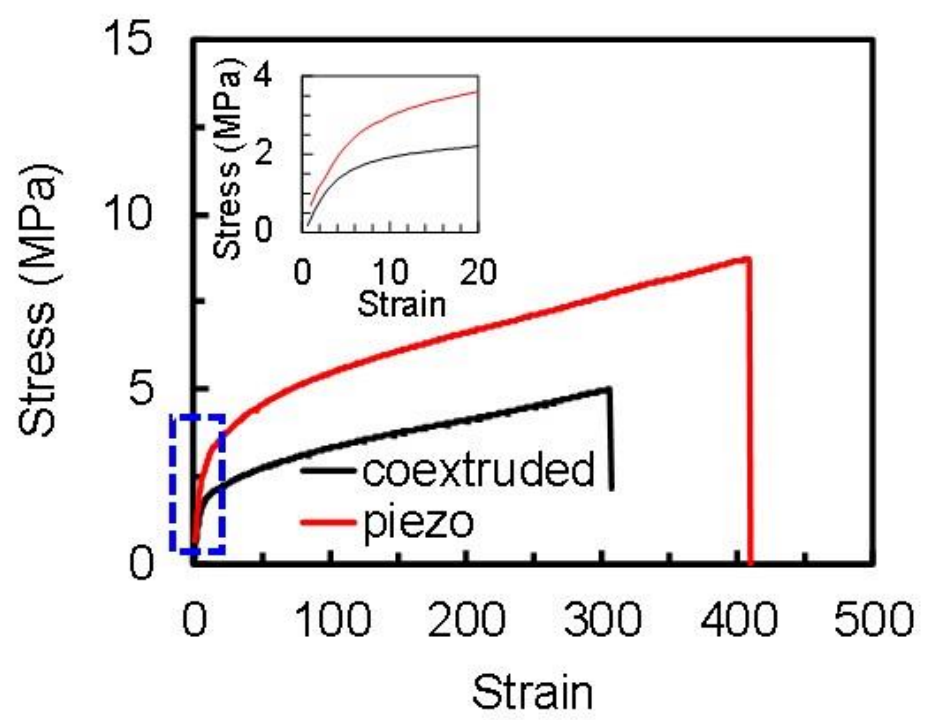

Figure S5. Representative tensile stress versus strain curves of the coextruded and piezoelectric filaments, inset: zoomed view of the elastic region.

Keeping silver to a minimum avoids its detrimental effect on the mechanical properties of the fiber, confirmed by mechanical tests. The coextruded filament exhibits a decrease in tensile strength (see Figure $\mathrm{S} 4$ for the stress -strain curve) from 8.1 MPa $\pm 0.9 \mathrm{MPa}$ to $5.6 \mathrm{MPa} \pm 0.5$ $\mathrm{MPa}$ (average of 5 values) and strain at break from $422 \% \pm 24 \%$ to $296 \% \pm 20 \%$ as compared with the extruded piezoelectric filament with similar dimensions. The Young's modulus of the piezoelectric filament is $19.8 \mathrm{MPa} \pm 2.9 \mathrm{MPa}$ and the one for the coextruded filament is $20.0 \mathrm{MPa} \pm 3.0 \mathrm{MPa}$. Both filaments present moduli, implying that electrodes do not significantly affect the compliance of the thread. This low value of elastic modulus results in increased mechanical sensitivity. ${ }^{21}$

\section{S6. Piezoelectric tests}




\section{WILEY-VCH}

To determine the piezoelectric properties, we measured the piezoelectric response from the filaments (distance between the grips $=12-15 \mathrm{~mm}, 3$ samples) using a dynamic mechanical analyzer (DMA Q800, TA Instruments) in multi-strain mode (1 \% strain, $2 \mathrm{~Hz}$; preload of 0.1 N) for 5 min each.

(a)
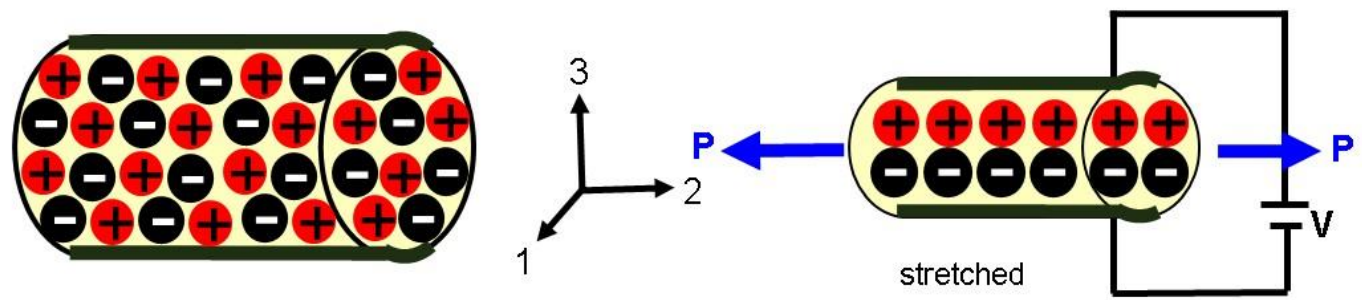

(b)

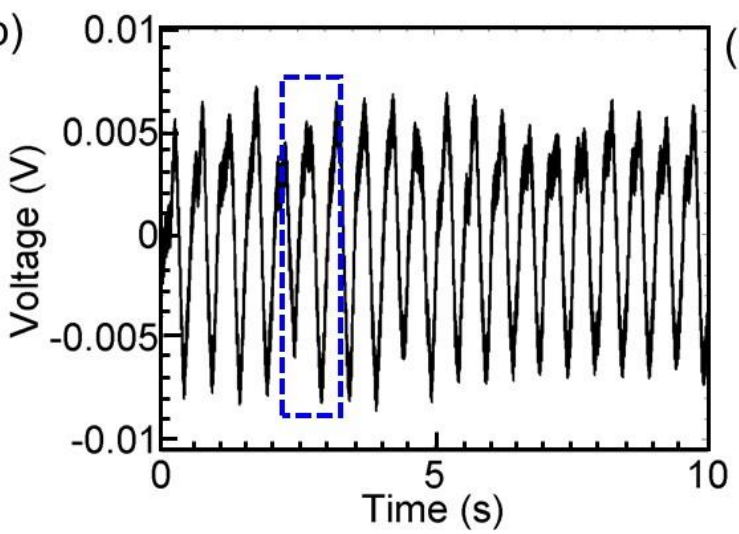

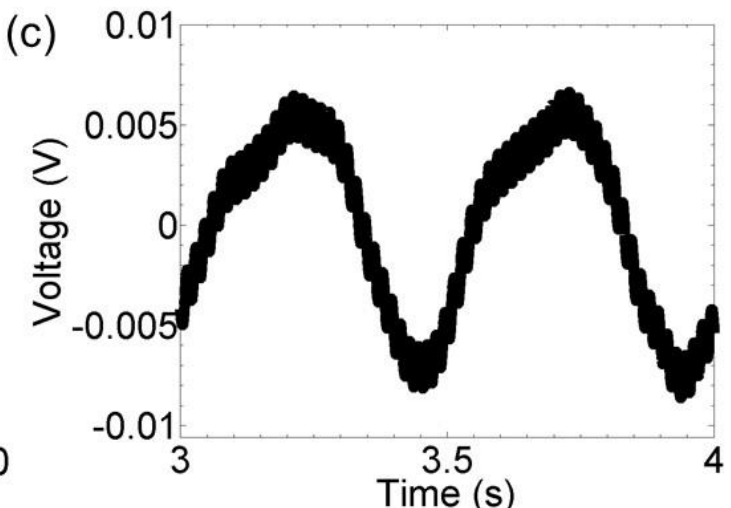

Figure S6. a) Schematic showing the piezoelectric phenomenon in the thread upon stretching in the longitudinal direction; b) a part of a representative response of one of the threads at $1 \%$ applied strain at $2 \mathrm{~Hz}$; c) single cycle voltage output as a function of time during the dynamic piezoelectric test of the thread (zoomed in view of the region in the blue box from $2 b$ ).

Piezoelectric materials are shown to measure the strain up to $1.2 \%^{21}$ and most human activities fall in the low frequency range of $0.25-2 \mathrm{~Hz} .^{25}$ We tested the piezoelectric thread under cyclic tensile loading with $1 \%$ strain at a frequency of $2 \mathrm{~Hz}$ using a dynamic mechanical analyzer. Figure $\mathrm{S} 5 \mathrm{~b}$ is a representative curve of the piezoelectric output from the sensor with respect to time. As the fiber is stretched along its length, charges are generated across its thickness (see schematic in Figure S5a). Figure S5c is an enlarged view of the piezoelectric response and the output signal clearly resembles the input sine wave.

\section{S7. Vibration tests for the aero-elasticity monitoring sensor}




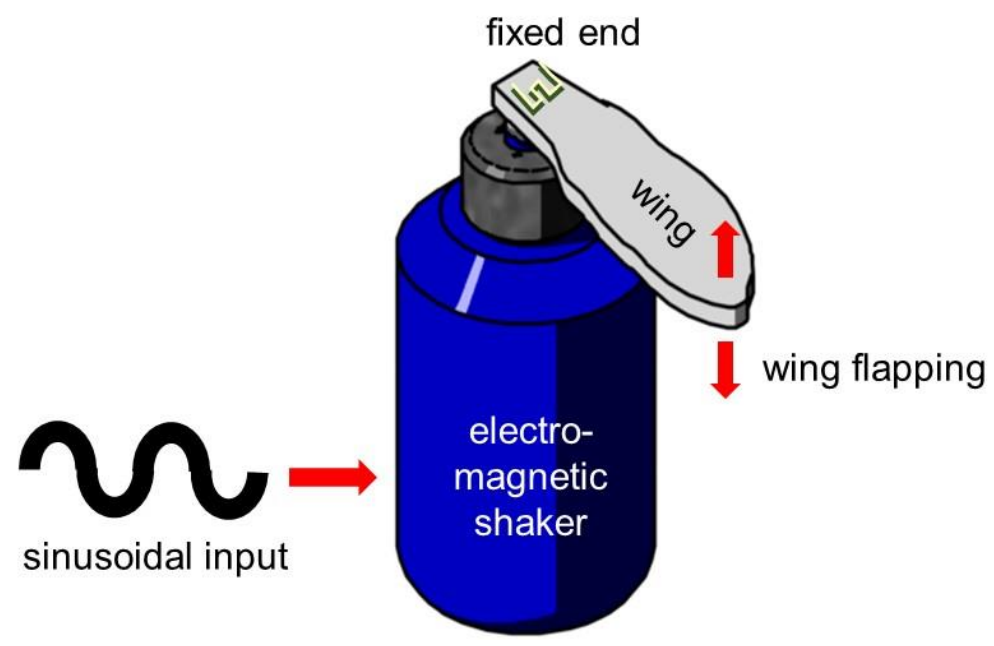

Figure S7. Schematic of the FDM printed wing mounted on an electromagnetic shaker and subjected to sinusoidal mechanical input.

\section{S8. Static motion analysis}

Preliminary tests with the knee-movement sensors involved the wearer raising and lowering the lower limb (from the knee to the foot) both upon sitting and while standing (see Figure S7a and b). Each exercise was filmed and then, analyzed using Kinovea (0.8.25 x 64) to monitor the movement of the ankle. The software included a motion tracker, that allowed the user to select a specific point in the video to monitor its movement along $X$ and $Y$ axes. The $X$ and $Y$ coordinates could be used to calculate the $\mathrm{R}$ values for each movement, $\mathrm{R}$ being the displacement of the ankle from the origin (the point at which the leg was at rest). Figure S7c and $\mathrm{d}$ show the comparison of $\mathrm{R}$ values of the ankle with the voltage response form the piezoelectric thread for the two tests. The piezoelectric signal of the instrumented knee stabilizer measured as the wearer raised the leg compared well with visual recordings analysed using Kinovea software. 


\section{WILEY-VCH}

(a)

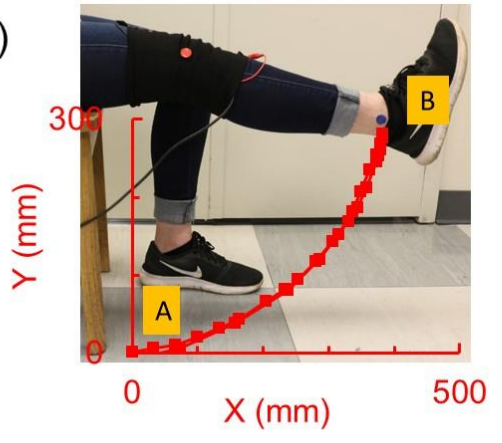

(c)

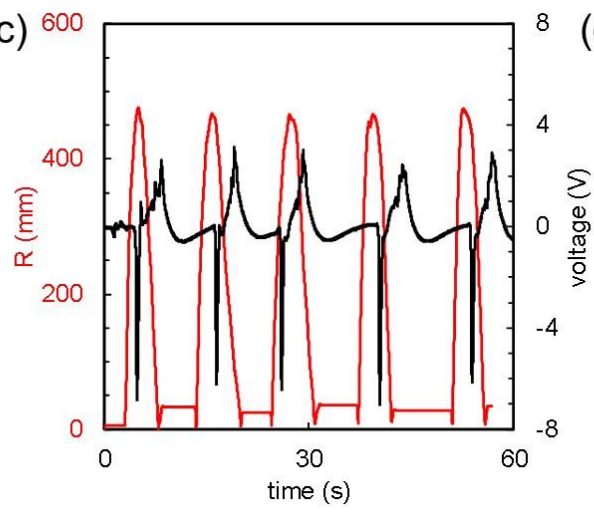

(b)
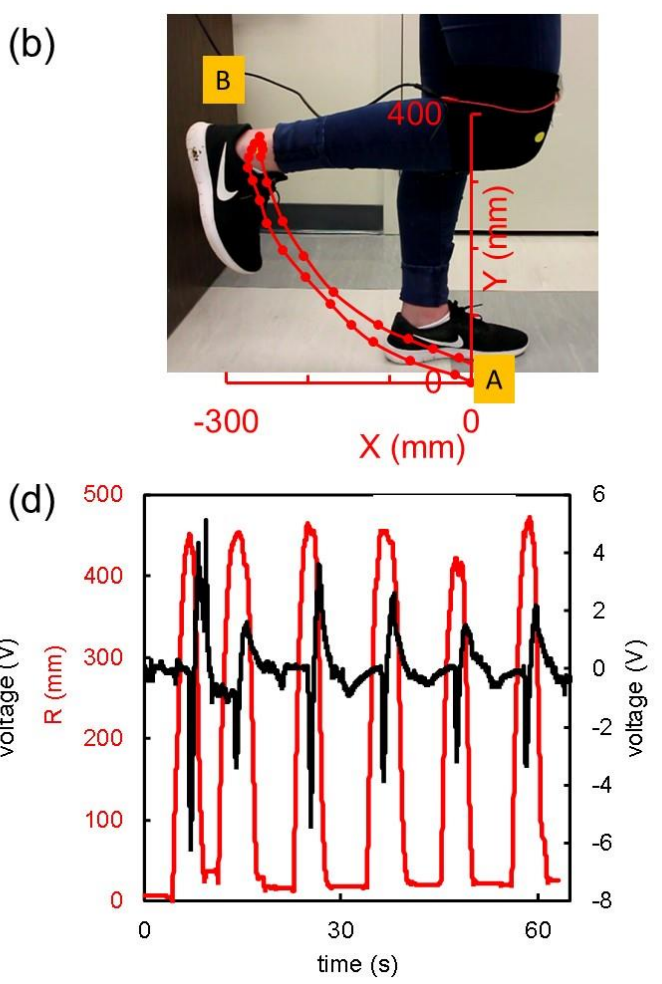

Figure S8. Simple leg raising tests a) sitting and b) standing. Red plots show the movement of the ankle from its initial to final position. Correlation between the output voltage versus ankle displacement (R) for five consecutive cycles c) sitting and d) standing.

\section{S9. Dynamic motion analysis}

For the cycling tests, the interior angle at the knee was obtained using Image J (win64), calculated for each frame (processed using MATLAB) from the recorded video (60 fps).

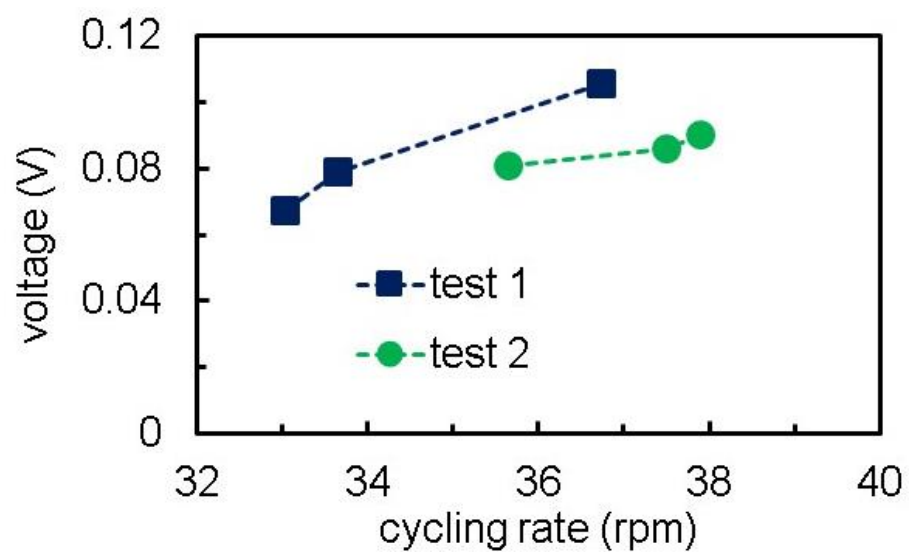

Figure S9. Peak voltage output per cycle as a function of cycling rate for two separate tests. 
S10. Respiration monitoring

Table S1. Number of breaths per minute for quick breathing.

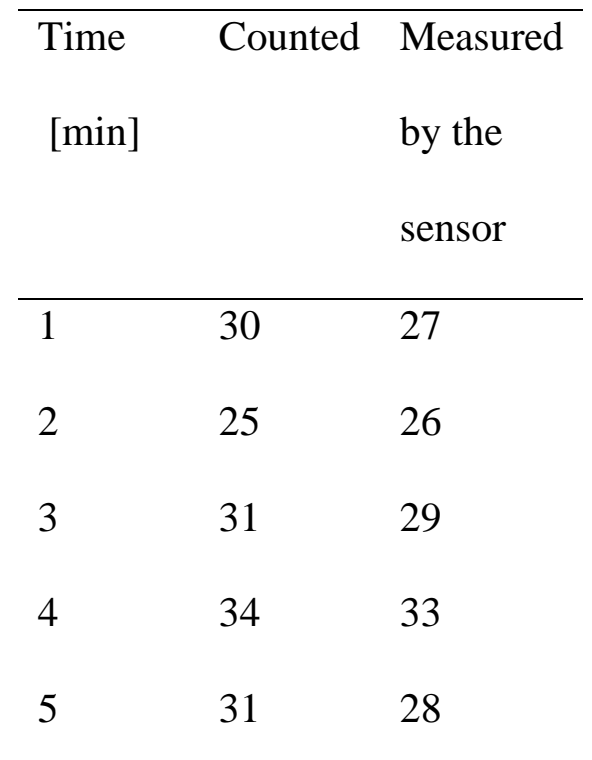

Table S2. Number of breaths per minute for deep breathing.

\begin{tabular}{|c|c|c|}
\hline $\begin{array}{l}\text { Time } \\
\text { [min] }\end{array}$ & Counted & $\begin{array}{l}\text { Measured } \\
\text { by the } \\
\text { sensor }\end{array}$ \\
\hline 1 & 6 & 6 \\
\hline 2 & 7 & 7 \\
\hline 3 & 7 & 7 \\
\hline 4 & 6 & 7 \\
\hline 5 & 7 & 7 \\
\hline
\end{tabular}

\section{S11. FDM printed structures}

We designed a hemisphere, a cat and a U-shaped structure for printing the spanning filaments in Catia V5. We obtained the cicada wing image from stillblog.net. We acquired the geometry of the image using Sketch Tracer tool in Catia V5. We acquired the design of the cat from Thingiverse.com. We then converted all the part files into .stl files. We used Leapfrog FDM printer to print all the above parts with PLA. 